\title{
IS NEUROLINGUISTIC PROGRAMMING A MYTH? A REVIEW OF NLP STUDIES
}

\author{
Faiza Zeb \\ Research Scholar, \\ Certified NLP Practitioner from American Board of NLP, \\ Virginia, USA \\ Email: faizamunaee66@hotmail.com
}

\author{
Ansa Hameed \\ Assistant Professor, \\ Department of English, Prince Sattam Bin Abdulaziz University, \\ Alkharj, KSA \\ Email: a.zahoor@psau.edu.sa \\ Shaista Zeb \\ Assistant Professor, \\ Department of English, NUML \\ Punjab, Pakistan \\ Email: szeb@numl.edu.pk
}

\begin{abstract}
NLP has not been able to gain the status of a scientific model since its emergence in 1970 's with certain reservations by the experts in the various fields such as educators, linguists, English language teachers, and scientists. Despite the fact that more than fifty organizations are working in the UK solely on NLP, there are only a few conversations and studies available on the subject due to mere supposition about the lack of scientific support for its existence. In NLP history, much work has been ignored due to mere speculation. Also, many researchers did not pay any attention to the theoretical and conceptual underpinnings of the NLP ideas and researches via ignoring various studies in this filed. This article has aimed at the exploration of NLP via various studies in diverse fields dealing with the varied aspects of NLP toolkit to illustrate the mammoth significance it holds. The research circumspectly examines the fundamental role that NLP plays in education, sports, health, and English language teaching practices that is beyond the claims of experts who declare it a pseudoscience.
\end{abstract}

\section{KEYWORDS}

$N L P$, education, English language teaching, other fields 


\section{INTRODUCTION}

\section{Origin of NLP}

Neurolinguistic Programming is generally attributed to the areas of neurology and linguistics. Since, Neurology refers to thought processes and linguistics indicates language processes (Freeth, 2015), human behaviour can be programmed via changing thought processes. The idea is not as simply as it seems; it has number of complexities to refer to.

The term Neurolinguistics was discovered while studying the connections between the intricate and complex areas of neurology and language. Since then, it has been struggling to decipher the processes of speech production and reception in human brain. However, considering human brain the most complex phenomenon of human existence on one hand and language as the most creative form of its expression on the other hand, Chomsky proposed the idea that all surface structure are the result of various deep structures. The one linguistic expression may be expressed in number of other ways and not accurately represent the underlying complex thought patterns. Owing to the fact, surface structures may only offer a glimpse of convoluted and complex deep structures; all those actions occurring at the surface level actually originate from deep level in the unconscious part (Tosey \& Mathison, 2003). However, if people focus, they may achieve whatever they intend to.

If we dig deep, NLP is not merely the business of the neurologists and linguists. The idea underneath this terminology of NLP had been driven from the vast fields of neurology, psychology, and linguistics in the late 1970's. The field of neuroscience is relatively new and all efforts to draw its connections with the areas of psychology, sociology, and language teaching, have been limited to few discussions only. The various NLP theories and models has laid emphasis on existence of intertwined, complex, and intricate thought patterns existing in human brains which can be shaped, reshaped or improved with the use of language patterns. The concept of modelling was in effect the imitation of linguistic patterns employed by renowned therapists and hypnotists Virginia Satir and Milton Erickson(Tosey \& Mathison, 2003).

The declared pioneers of NLP, John Grinder and Richard Bandler wrote various books to provide the ways to deal with intricate and complex human behaviour. They presented numerous tools which may assist professionals belonging to numerous fields of life to understand intricacies belonging to human behaviour. Grinder and Bandler, introduced diverse strategies that are verbal as well as non-verbal since communication patterns may be both verbal and non verbal. The ongoing thought processes which occur in unconscious part may be depicted via linguistic as well as paralinguistic patterns which reveal the conscious human mind. Michael Gazzaniga (2009) explains convoluted and multifaceted connection between the conscious and unconscious mind 
via raising certain questions: for instance, how the interconnection between how we feel and how we speak is unified and how it becomes possible for us to change the way we want the actions to be done.

The multifarious connection between unconscious and conscious to get the desired results is essentially the reason to coin the concept of NLP. Various studies suggested NLP a commendable tool to change people's perception regarding any existing notion in their mind via the use of linguistic experiences which has also been practiced by eminent hypnotists and therapists. Therefore, the first research journal of NLP appeared in 2009(Weaver, 2009) to develop understanding in terms of actual NLP applications in numerous fields of human life. The pioneers of NLP , Grinder and Bandler(1979), consider it a commendable instrument for bringing about significant changes in people's perceptions of the world. Their discovery of this magical tool is a result of their minute observation of the renowned therapists for instance: Virginia Satir, and Milton Erickson.

\section{Definitions}

There have been presented and proposed various definitions of this approach, few are given below:

Rogers (1986) defines NLP as a method of "realness or genuineness" that may be "highly effective".

Gibbons, Limoges, Nowotny, Schwartzman, Scott, and Trow (1994) declare NLP as an amalgamation of various theories and approaches from psychology and neurology to gain access to intricate and complex human mind.

Jane Revell (1997) views NLP as a tool for providing people with opportunities and assisting them in realizing their latent potential.

Lavan (2002) accredits NLP to create changes and bring improvement to not merely individuals but the whole organizations.

For Tosey and Mathison (2003), NLP is both a theory and a method to understand complex human behaviour to take certain practical steps accordingly.

Tosey, Mathison and Michelli(2005),suggest NLP as a methodology to discover one's subjective experience. According to them, NLP is a product of "Patterned connections between internal experiences (neuro), language (linguistic) and behaviour(programming)".

Yemm (2006) identifies NLP as a set of guiding principles to gain desired results. Singh and Abraham (2008) recognize NLP as constructive and productive set of techniques to endure stress and time management in any institution or organization. For German and Churches (2009), NLP develops not only communication between individuals but also creates self awareness that guides towards personal development. Further, Churches(2009), states the significant aspect of NLP as neuro, which with the 
aspect of linguistics does programming to gain results.

Lazarus(2010) acclaims NLP a significant tool to bring numerous changes and desired results.

In Ready and Burton's standpoint (2010), NLP is a combination of three significant parts: the first part of neuro indicates the procedure that may activate or trigger the neurological system; the second part of linguistic refers to the way that illustrates the role of language to influences the experience; and the third part of programming helps to code the experience.

According to Mercer (2014), NLP is a powerful technique for recognizing people's hidden potential to attain their goals.

These indispensable features offer an ample amount of evidence to characterize NLP as a valuable tool for whatever purpose one wants to utilize it.

\section{Few presuppositions regarding NLP techniques}

In NLP, the concept of Presuppositions depicts a succession of suppositions/statements which may lead to an effortless and effective communicative process. The four most significant presuppositions generally agreed upon are illustrated by Wake in the following manner (2010):

1. Map itself is not the territory it refers to; there are various versions of reality and truth differs from person to person and from one community/generation to another. The reason of this presupposition of NLP is to see how map of an individual can be made constructive and creative.

2. The second presupposition denotes people's intentions. Secondly people respond in accordance with what they have understood. In case people do not dig up what they are interested in, means they should ponder the ways from which their desired response may be elicited.

3. The third states- "Mind and body form a cybernetic system" (p.10). The subjective experiences are unique to humans and can be modified accordingly via employing certain strategies. To make it comprehensible, one can say that mind and body affect each other and can be controlled by each other. We can do physically whatever we intend to do mentally and vice versa.

4. According to the fourth presupposition (2010), which refers to the idea of cognitive linguistics, people only have to activate the resources (one's inner potential) which they already possess. It is just necessary to locate these resources in order to activate them. Pelz and Halls(2007), therefore, consider NLP as related to Human Potential Movement.

In fact, all of the aforementioned presuppositions are crucial for receiving valuable response or the desired behavior from others. However, these presuppositions inculcate many scholars to consider NLP as a pseudoscience. They deny individuals' 
intellectual and emotional modification which lead to their refined and developed behaviour via linguistic tools. Demico(2016)affirms in his lecture to the graduate students about identifying the pseudo scientific claims and NLP falls to be pseudo science in his perspective. Also, John Stevens(2020), perceive the current teachings of NLP as 'collective' instead of dealing with them individually to discover their validity since he validated meta program in connection with Piaget's idea of disequilibrium. Also he emphasized upon his newly constructed theory of self development of far more worth than NLP claims. Vigil(2016)as a counter argument mentions NLP as may not be the part of science but its connection with the fields of neurolingusitics, neurophysiology and problem-oriented psychotherapy, cannot be ignored due to ample contribution of these fields to scientific knowledge of NLP. According to Sanghvi(2020), people disrespect, discredit and disown NLP on the grounds of : hypnosis, learning and teaching manipulation, pseudoscience, unscientific, false and fake psychology, and unproven behavioural changes but still NLP works and many take classes and employ its techniques to bring change. Since humans are basically all emotions and their psychological process vary in connection their society and norms. If something works for them then it is worth using.

\section{An inquiry into studies in Education \& English language teaching in relation to NLP}

NLP studies have been found in various fields but our focus in this paper is one education and ELT world to illustrate the significance of NLP and examine its valuable contribution which has not been given worthy consideration by many experts of these fields.

\section{NLP in Education}

Brown (2004) via explaining the important terminology of Meta programmes of NLP in his work "What makes a good educator?" illustrates varied teaching styles. The qualitative inquiry considers monotonous teaching styles a cause to de-motivate students. The lack of acquaintance of teachers and students' Meta programmes only brings distraction from teaching lessons and deprivation of available resources.

Reupert and Maybery in: "Applying Ericksonian languaging and NLP Principles to Educational Setting" (2005), confer upon the implication of hypnotic principles in the field of education. The study corresponds to the initiative taken by Oldridge(1982) that appreciates many teachers who are not aware of their unconscious use of hypnotic practices. This idea traces its roots from Milton's hypnotic practices and Conway's idea (2002) that students come from diverse backgrounds possessing complex and intricate individual thought processes.

Wood (2006) conducted three separate but related researches. He aims to distinguish 
the essential existence of nonverbal signals to their relevant representational systems in: "NLP revisited: nonverbal communications and signs of trustworthiness." The first study explores its connection to representational systems. The second study corresponds to nonverbal cues as a significant source to win trustworthiness via establishing rapport. The third study focuses on the understanding of nonverbal cues possessed by the customers. This study significantly strengthens the usefulness of NLP techniques to gain desired results.

Further, in their work titled "Neuro-linguistic programming as an innovation in education and teaching," Tosey and Mathison (2010) discuss the impact of NLP in educational settings and teaching tactics. Given the paucity of scholarly work on NLP to date, this essay provides a well-informed foundation and reflection of employing NLP strategies and principles for coaches, teachers, counselors, guides, and mentors.

Tomasz Witkowski (2010) illustartes the concept and theoretical foundations of NLP in his essay "Thirty-Five Years of Research on Neuro-Linguistic Programming." For this inquiry, he chose quantitative analysis of only those studies which he found more robust and empirical. He found majority of the studies contradicting the basic claims and ideas of NLP For the reason that he could not see NLP studies existing on empirical grounds in most of the studies; he raises questions on credibility of NLP. However, his research does not take into consideration the basic tenet of NLP as well; it is a subjective inquiry into humans to get desired results. Another research, "Neurolinguistic programming and learning: Teacher case studies on the impact of Neurolinguistic programming in education", was carried on 24 teacher-led action research case studies by experts in education. In this research project, many teachers were trained in NLP to examine the credibility of NLP techniques (Carey, Churches, Hutchinson, Jones, \& Tosey, 2009). The project illustrates the effectiveness of NLP principles and techniques via various lengthy and significant case studies and incorporating people's views after having trained in NLP. This study deserves praise for incorporating 111 NLP-related academic publications and references. This research can be considered as a hallmark to see effectiveness of NLP techniques.

Kudliskis and Burden (2011) conducted their research on 36 first year students from a secondary school in the South West of England, to examine if NLP could make students get over their exams without developing the feelings of anxiety and stress. They looked at a few minor but significant parts of NLP. For example, the impact of learners' assumptions on exam performance and how to use NLP approaches to alter established cognitive patterns. The study shows that NLP tactics can help students achieve better exam outcomes as a result of teachers' attempts to help students lower their affective filter, considering their responses merely in the category of responses despite declaring them as right or wrong. 


\begin{abstract}
Alghafri and Ismail (2011), used thinking methods based on the neuroscience paradigm to see how effective they were in a learning setting. They tried to bridge the neuroscience and education divide. The ideas of cognitive neuroscience and neurolinguistics are at the foundation of this method. Much research sustains the idea to add neuroscience-based thinking skills (NBT) in the syllabus that might help pupils enhance and supplement their higher-order thinking abilities. The information was gathered from 62 Malaysian primary school pupils. Out of 62 , thirty students were placed in NBT group. The results revealed a significant distinction between both groups. The findings also show that the diverse learning environments (combined with distinct strategies, syllabuses, and procedures) resulted in different outcomes.
\end{abstract}

The majority of research publications debates the usage of NLP in classroom practice and come to a good conclusion. A strong emphasis is placed on the usage of influential linguistic patterns. Other notable study topics included the application of NLP in leadership development. Meta programs in NLP have also been the subject of several researches. Creativity and self-expression are two further areas where several beneficial researches have been conducted. Several researches have been performed with the purpose of demonstrating the application of NLP in academia, and in teacher professional behaviour. Also, many teachers aspire to become NLP experts after attending NLP training sessions.

\title{
NLP in English language teaching
}

Only in the last few years has Neurolinguistic Programming piqued the interest of language educators. Several studies on the impact of NLP on various teaching approaches have been performed; however they are few and far between. The majority of them are centered on debates over the application or efficacy of Neurolinguistic Programming.

Richards and Rodgers (2001) were also the first to introduce NLP as an additional skill in the teaching of English as a second language. According to Millroad (2004), it is "an approach to language instruction that is supposed to help create excellence in learner performance." Millrood (2004) used workshops with teachers to strengthen teachers' understanding of NLP in the classroom discourse in his paper "The Role of NLP in Teachers' Classroom Discourse. The program included 16 experienced secondary English instructors, all of whom had at least 5 years of experience in the classroom. Building rapport with students, motivating answers from students as a result of leading them, recognizing, and monitoring their emotional states of mind, and distinct learning styles were all covered in the course. The workshop's agenda said that the more trust students have in their professors, the more successfully they learn. It is worth mentioning that a classroom discussion can lead learners to either sense of accomplishment or failure. 
Tatjana (2009) in the research article titled 'Teachers' Professional Identity-A study into how teachers in one Slovenian primary school reflect their professional identity and work'. For NLP-based continued professional development, there were two sets of teachers (CPD). Fourteen teachers (who were not NLP trained) were placed in the experimental group and the other sixteen (who were being trained in NLP) were in the control group. The trained teachers used more terms that had a constructive, encouraging, or positive connotation. Other teachers who were not part of the training, on the other hand, used more words having a negative connotation.

John West-Burnham (2010)in his study on implications of NLP, challenged traditional language teaching views, concluding that students and teachers alike gained more confidence in the class when using this method. This study challenged previously held assumptions about language education, as a result of learners' increased ability to convey their sentiments. As a result of the NLP procedures, they were also more driven. It also focused on the practical aspects of NLP approaches, emphasizing their utility.

In the study "The Study of EFL Teachers' Discourse in Reading Skills Using Bloom's Cognitive Taxonomy," thirty two classes were observed by Zargham Ghabanchi, Mostafa Morady Moghaddam, and Shirin Malekzadeh (2011). The classes were examined in three phases: before, during, and after reading. They used Bloom's Taxonomy to look at learners' cognitive states in order to see how teachers' dissatisfaction affects learners' proficiency levels. Their main goal was dealing with important cognitive areas as responsible during the educational process. They focused on the teachers' action verbs in order to determine their impact on language learners.

Pishghadam, Shayesteh, and Shapoori (2011) discuss the importance of communication in the classroom via designing and validating the scale of NLP for EFL learners. The goal of this study was to construct and then validate an NLP questionnaire in order to use it as an example. The study featured two stages, with 175 English as Foreign Language (EFL) teachers in the first and 93 EFL teachers in the second. Students are given improved opportunity to study efficiently when NLP tactics are used. The importance of this questionnaire rests in the creation of an NLP scale that can be quite useful to NLP academics.

The study's findings also support the usage of NLP aspects in education. It bolstered the argument that NLP, as a crucial idea in humanistic psychology, is well-suited to communication skills. Khabiri and Farahani (2014) tried to investigate the impact of either NLP or NLP as well as critical thinking on performance of EFL learners. They conducted their research on "EFL learners' reading comprehension and vocabulary retention". While NLP and critical thinking showed little influence on language 
retention, critical thinking abilities modified people's thinking patterns. Ramganesh and Paulraj(2015)'s research on 45 teacher educators in India to determine their level of expertise with NLP approaches, with a focus on individual distinctions that are critical for teachers to recognize. Building rapport, cognitive and emotional stimulants, and elicitation approaches have all been highlighted for usage in school custodial situations.

As previously said, all of the studies tried to establish the existence and significance of NLP in various elements of English language Teaching. However, due to a lack of understanding as a language teaching strategy and the inclusion of more neurological factors, NLP has not been identified as an extensively explored field around the world. Teachers, according to Swan (1985), deny the exposure to innovations in English language teaching. They find it quite hard to adapt the new methodologies and keep relying on old ways and their common-sensical techniques

\section{RESEARCH OBJECTIVES}

1. To understand the immense significance associated with NLP particularly in the last decade

2. To reveal some pseudoscience aspects of NLP and their counter arguments

3. To explore the authenticity and realness of NLP claims by its pioneers and followers in various fields via observing diverse studies

\section{RESEARCH QUESTIONS}

1. Why is NLP given immense significance in the last decade?

2. What are some of the claims which make NLP pseudoscience?

3. How can the authenticity and realness of NLP be examined?

\section{RESEARCH METHODOLOGY}

In order to carry out this review research, the researcher has presented the few already existing studies and viewpoints of the other researchers from the fields of education and English Language Teaching in accordance with their claims and studies in NLP. A review article may be of various types such as: systematic, narrative, or metaanalysis (Majumder, 2015). This study follows narrative review where existing literature is presented and critiqued to develop inclusive understanding vis-à-vis the research questions and objectives.

\section{FINDINGS \& DISCUSSION}

NLP doctrine is straightforward but admirable, which makes it difficult for people to embrace it scientifically and academically. Another factor for NLP's lack of acceptance as a theory among ELT professionals is its practical applicability in a variety of domains. Humanistic philosophy, for example, is highly suited to ELT techniques. 
That is why, despite the fact NLP and the previous teaching methods such as: Suggestopedia, Silent Way Method, and Community Language Learning, posses common features, linguists have refused to acknowledge it as a component of ESL/EFL teaching and learning process. Furthermore, Further, NLP theories are simple to understand for both language teachers and learners, as they do not contain any complications that would make them incomprehensible to others. Tony Harris (2001) declares everything that possesses the tiniest element of linguistics is applicable to language teachers. Also, anything that demonstrates a link between mind and language becomes a crucial part of either psycholinguistics or cognitive linguistics.

According to Paul Tosey and Jane Mathison (2001), there are a few significant reasons for academics not to accept NLP as a theory. For example, since NLP pioneers began learning the many procedures in order to utilize them magically, academicians have needed to look for some theory to recognize their practical value. However, the NLP world can deem this claim untrustworthy because effective practice is entirely dependent on cognitive comprehension. In addition, its importance has been questioned due to the merger of multiple unclear notions and disjointed theories; yet, if NLP is defined solely as a set of methods, as described by Craft (2001), it still has theoretical unity in its epistemology.

NLP's importance has also been questioned due to the merger of multiple unclear notions and disjointed theories; nevertheless, if NLP is defined solely as a set of methods, as provided by Craft (2001), it still retains theoretical unity in its epistemology.

However, if NLP techniques are ineffective, the following questions must be considered: Why are there so many NLP courses available around the world? Why do so many people sign up for training on their own? If you can't attend live training from professionals, why are there so many online programs? How do people feel after receiving training? Do they feel better than they did before? Why have professionals from other domains conducted NLP research?

To conclude, NLP has not been included in scholarly study, and authorities have labelled it a pseudoscience. There have been specialists who have assertively challenged Chomsky's beliefs about language's innateness, and there are many who do not believe NLP has any value.

\section{RECOMMENDATIONS}

There is enough room to perform NLP research as part of ELT practices, which have been rejected in the past. Furthermore, no research studies revealed an in-depth theoretical grasp of language patterns, which were basically behind the initiation and development of this concept of NLP. 
Also, no studies have looked into how language patterns become prominent. In addition, no study has found the critical link between language patterns and human emotional and cognitive abilities, which is a part of the NLP approach. Similarly, no research has been performed on 'how teachers' perceptions influence their students' behaviour'.

\section{REFERENCES}

Al-Alwan, A., Asassfeh, S., \& Al-Shboul, Y. (2013). EFL Learners' Listening Comprehension and Awareness of Metacognitive Strategies: How Are They Related?. International Education Studies, 6(9), 31.

Alghafri and Ismail Allan, F., Bourne, J., Bouch, D., Churches, R., Dennison, J., Evans, J., ... \& Rhodes, L. (2012). Training in Influencing Skills from Neuro-Linguistic Programming (Modelled from Hypnosis and Family Therapy), in Combination with Innovative Maths Pedagogy, Raises Maths Attainment in Adult Numeracy Learners. Online Submission.

Bashir, A. \& Ghani, M. (2012). Effective Communication and Neurolinguistic Programming. Pak. J. Commer. Soc. Sci. 6(1), 216-222.

Brown, N. (2004). What makes a good educator? The relevance of meta programmes. Assessment \& Evaluation in Higher Education, 29(5), 515-533.

Carey, J., Churches, R., Hutchinson, G., Jones, J., \& Tosey, P. C. (2009). Neuro-linguistic programming and learning: Teacher case studies on the impact of NLP in education.

Churches, R., \& Terry, R. (2008). NLP for Teachers How to be a highly effective teacher. Crown House Publishing.

Craft, A. (2001). Neuro-linguistic Programming and learning theory. Curriculum Journal, 12(1), 125-136. doi:10.1080/09585170010017781

Dilts, R., \& Epstein, T. (1995). Dynamic learning (Vol. 426). Cupertino, CA: Meta Publications.NLP new coding. NLP University Press.

Doemland, J. H. (2001). Language and performance: An NLP meta-model analysis of performance descriptions by elite canoe-slalom athletes. Dissertation Abstracts International, B. Sciences and Engineering, 61(10-B), 5267-B

Damico, Jack. (2016). Re: Neuro-linguistic Programming, Myth or Reality?. Retrieved from: https://www.researchgate.net/post/Neurolinguistic_Programming_Myth_or_Reality/583c5cb5615e2706b74a4f14/citation/do wnload.

Dowlen, A. (1996). NLP - help or hype? Investigating the uses of neuroLinguistic Programming in management learning. Career Development International, 1, 27-34.

Ghabanchi, Z., Morady Moghaddam, M., \& Malekzadeh, S. (2011). The Study of EFL Teacher Discourse in Reading Skill Using Blooml's Cognitive Taxonomy. International Journal of Linguistics, 3.

Gibbons, M., Limoges, C., Nowotny, H., Schwartzman, S., Scott, P., and Trow, M., 1994. The New Production of Knowledge, Sage, London.

Grinder, J. \& Bandler, R. 1976. The Structure of Magic II. A Book about Communication 
and Change. Palo Alto, California: Science and Behavior Books, Inc.

Harris, T. (2001). NLP if it works use it. CAUCE, Revista de Filología y su Didáctica, 24, 29-38.

Hosseinzadeh, E., \& Baradaran, A. (2015). Investigating the relationship between Iranian EFL teachers' teaching styles and their Neuro-linguistic programming. International Journal of Academic Research. http://dx.doi.org/10.7813/2075-4124.2015/7-3/B.10

Kandola, A. (2017). What is NLP and what is it used for? Retrieved from https://www.medicalnewstoday.com/articles/320368.php

Kong, E. (2012). The Potential of Neuro-Linguistic Programming in Human Capital Development. The Electronic Journal of Knowledge Management, 10(2), 131-141.

Kudliskis, V., \& Burden, R. (2009). Applying ,what works ${ }^{\text {ee }}$ in psychology to enhancing examination success in schools: The potential contribution of NLP. Thinking Skills and Creativity, 4(3), 170-177.

Lavan, I. (2002) "NLP in business - or more than a trip to the zoo", Industrial and Commercial

Lazarus, J. (2010). Successful NLP. Crimson.

Linder-Pelz, S. \& Hall, L. M. (2007). The theoretical roots of NLP-based coaching. The coaching Psychologist, 3(1), 12-17.

Mainwaring, S. \& Skinner, H. (2009). Reaching donors: Neurolinguistic programming implications for effective charity marketing communications. The Marketing Review, 9(3), 231-242.

Majumder, K. (2015). editage insights . Retrieved from https://www.editage.com/insights/6article-types-that-journals-publish-a-guide-for-early-careerresearchers\#: :text=Review\%20articles\%20can\%20be\%20of,the $\% 20$ journal\%20and $\% 20$ subject\%20area.

Metcalf, T. (2018). Examples of Neuro-Linguistic Programming in the Workplace. Retrieved from The Nest: https://woman.thenest.com/examples-neurolinguistic-programmingworkplace-18150.html

Pishghadam, R., Shayesteh, S., \& Shapoori, M. (2011). Validation of an NLP scale and its relationship with teacher success in high schools. Journal of language teaching and research, 2(4), 909-917.

Pishghadam, R., \& Shayesteh, S. (2014). Neuro-linguistic programming (NLP) for language teachers: revalidation of an NLP scale. Theory and Practice in Language Studies, 4(10), 2096.

Ramganesh, E., \& Paulraj, I. J. M. (2015). Prospective Teacher Educators’ Awareness towards the Key Components of NLP.

Revell, J., \& Norman, S. (1997). In your hands: NLP in ELT. Saffire Press.

Richards, J. C., \& Rodgers, T. S. (1986). Communicative language teaching. Approaches and Methods in Language Teaching. New York: Cambridge UP.

Richards, J. C., \& Rodgers, T. (2001). Approaches and methods in language teaching (2nd ed.). New York: Cambridge University Press.

Sanghvi, A. (2020). The myths and misconceptions about NLP(Neuro Linguistic Programming). Retrieved from https://amisangvi-30.medium.com/the-myths-andmisconceptions-about-nlp-neuro-linguistic-programming-898a5c705b55

Sarmdiyan, S., \& Pouyamanesh, J. (2012). Investigating the Effectiveness of Teaching 
Neuro-Linguistic Programming Strategies on High School Students' SelfEsteem. American Journal of Scientific Research, (69), 10-19.

Singh, A., \& Abraham, A. (2008). Neuro linguistic programming: A key to business excellence. Total Quality Management \& Business Excellence, 19(1/2), 141-149. doi:10.1080/14783360701602353

Skinner, H. and Croft, R. (2009) NeuroLinguistic Programming techniques to improve the self-efficacy of undergraduate dissertation students, Journal of Applied Research in Higher Education, 1: 1: 9-38.

Stevens, Darren. (2020). Re: Neuro-linguistic Programming, Myth or Reality?. Retrieved from: https://www.researchgate.net/post/Neurolinguistic_Programming_Myth_or_Reality/5f1e99533ed085424555d58a/citation/do wnload.

Tatjana, D. (2009). Teachers' Professional Identity. EdD Dissertation: The Open University. Available at http://www.humancc.org/tatjana_dragovic_doctoral.pdf

Tosey, P., \& Mathison, J. (2003). Neuro-linguistic programming and learning theory: A response. The Curriculum Journal, 14(3), 371-388.

Tosey, P., Mathison, J. \& Michelli, D. 2005. Mapping Transformative Learning. The Potential of Neuro-Linguistic Programming in Journal of Transformative Education, $3: 2: 140-167$.

Vigil, José Luis. (2016). Re: Neuro-linguistic Programming, Myth or Reality?.

Retrieved from: https://www.researchgate.net/post/Neurolinguistic_Programming_Myth_or_Reality/583e22d1f7b67efee528b54e/citation/dow nload.

Wake, L. (2010). Nlp: Principles in practice. Ecademy Press.

Weaver, M. (2009). An exploration of a research-based approach to the evaluation of clients' experience of neuro-linguistic psychotherapy within a private practice making use of the CORE model. In Current Research in NLP: Proceedings of 2008 NLP Conference (Vol. 1, pp. 67-83).

Witkowski, T. (2011). Thirty-Five Years of Research on Neuro-Linguistic Programming. NLP Research Data Base. State of the Art or Pseudoscientific Decoration?. Polish Psychological Bulletin, 41(2), 58-66.

Wood, J. A. (2006) "NLP revisited: Non-verbal communications and signals of trustworthiness", Journal of Personal Selling and Sales Management, Vol 26, No. 2, pp.197-204

Yemm, G. (2006) "Can NLP help or harm your business?", Industrial and Commercial Training, Vol 38, No. 1, pp.12-17. 